\title{
Synaptic Overflow of Dopamine in the Nucleus Accumbens Arises from Neuronal Activity in the Ventral Tegmental Area
}

\author{
Leslie A. Sombers, ${ }^{1}$ Manna Beyene, ${ }^{3}$ Regina M. Carelli, ${ }^{2,3,4}$ and R. Mark Wightman ${ }^{1,3,4}$ \\ Departments of ${ }^{1}$ Chemistry and ${ }^{2}$ Psychology, ${ }^{3}$ Curriculum in Neurobiology, and ${ }^{4}$ Neuroscience Center, University of North Carolina at Chapel Hill, Chapel \\ Hill, North Carolina 27599-3290
}

\begin{abstract}
Dopamine concentrations fluctuate on a subsecond time scale in the nucleus accumbens (NAc) of awake rats. These transients occur in resting animals, are more frequent following administration of drugs of abuse, and become time-locked to cues predicting reward. Despite their importance in various behaviors, the origin of these signals has not been demonstrated. Here we show that dopamine transients are evoked by neural activity in the ventral tegmental area (VTA), a brain region containing dopaminergic cell bodies. The frequency of naturally occurring dopamine transients in a resting, awake animal was reduced by a local VTA microinfusion of either lidocaine or ( \pm )2-amino,5-phosphopentanoic acid (AP-5), an NMDA receptor antagonist that attenuates phasic firing. When dopamine increases were pharmacologically evoked by noncontingent administration of cocaine, intra-VTA infusion of lidocaine or AP-5 significantly diminished this effect. Dopamine transients acquired in response to a cue during intracranial self-stimulation were also attenuated by intra-VTA microinfusion of AP-5, and this was accompanied by an increase in latency to lever press. The results from these three distinct experiments directly demonstrate, for the first time, how neuronal firing of dopamine neurons originating in the VTA translates into synaptic overflow in a key terminal region, the NAc shell.
\end{abstract}

Key words: in vivo voltammetry; neurotransmission; carbon-fiber microelectrode; cocaine; intracranial self-stimulation; burst firing

\section{Introduction}

Dopaminergic neurons provide a critical modulatory influence in reward seeking (Everitt and Robbins, 2000; Phillips et al., 2003a), prediction error (Schultz et al., 1997) and reinforcement (Wise, 2004). Real-time dopamine neurotransmission in awake animals, monitored with fast-scan cyclic voltammetry at carbonfiber microelectrodes, has revealed naturally occurring, subsecond dopamine concentration fluctuations (transients) in the nucleus accumbens (NAc) (Robinson et al., 2002; Wightman et al., 2007). Under basal conditions these transients occur at highly variable frequencies with amplitudes of $\sim 50 \mathrm{~nm}$ and durations of $\sim 1$ s (Wightman et al., 2007). They are enhanced upon administration of drugs of abuse (Stuber et al., 2005), and become timelocked to cues that predict reward availability (Phillips et al., 2003a; Roitman et al., 2004; Day et al., 2007; Owesson-White et al., 2008). Despite their importance, the origin of dopamine transients in the NAc is unclear.

The most likely cause of dopamine transients is phasic firing of dopaminergic neurons in the ventral tegmental area (VTA).

Received Nov. 17, 2008; revised Jan. 8, 2009; accepted Jan. 8, 2009.

This work was supported by National Institutes of Health Grants F32 DA 021061 (L.A.S.), DA 10900 (R.M.W., R.M.C.), and DA 17318 (R.M.C., R.M.W.). We thank Satoshi Ikemoto, National Institute on Drug Abuse; Andrew Young, University of Leicester; and Elyssa Margolis, Ernest Gallo Clinic and Research Center, University of California, San Francisco. Reema Padia, Jennifer Morton, Ellen Ambrose, Liza Rathbun, Robert Wheeler, Thomas Guillot, and Jennifer Ariansen provided experimental assistance. The instrumentation was designed and built at the University of North Carolina Electronics Facility, Department of Chemistry.

Correspondence should be addressed to Dr. R. Mark Wightman, Department of Chemistry, University of North Carolina at Chapel Hill, Chapel Hill, NC 27599-3270. E-mail: rmw@unc.edu.

DOI:10.1523/JNEUROSCI.5562-08.2009

Copyright $\odot 2009$ Society for Neuroscience $\quad$ 0270-6474/09/291735-08\$15.00/0
These neurons normally fire in a tonic pattern $(\sim 5 \mathrm{~Hz})$ and periodically discharge in short bursts $(\sim 20 \mathrm{~Hz})$. Bursts are particularly apparent at presentation of primary rewards or their associated cues (Schultz et al., 1997; Hyland et al., 2002). The activity of dopaminergic neurons is regulated by multiple inputs (Floresco et al., 2003; Lodge and Grace, 2006), and in brain slices that lack these inputs, phasic activity is not observed (Overton and Clark, 1997). In the intact brain the transition from tonic to phasic firing is caused by excitatory amino acids in the VTA (Overton and Clark, 1992; Chergui et al., 1993). Consistent with this, microdialysis studies revealed that activation of NMDA receptors in the VTA causes an increase in NAc extracellular dopamine (Karreman et al., 1996; Kretschmer, 1999). However, a direct assessment of the release consequence of phasic firing in the VTA requires rapid dopamine measurements.

Although VTA cell firing is a likely origin of dopamine transients, other factors may contribute. First, dopamine release is not always directly proportional to the degree of VTA activation, but can exhibit facilitation or depression (Montague et al., 2004; Kita et al., 2007). Moreover, terminal mechanisms may alter release. For example, glutamatergic inputs from the basolateral amygdala to the NAc modulate dopamine efflux (Howland et al., 2002), and nicotinic and opiate receptors on dopamine terminals can locally influence dopamine release probability (Zhou et al., 2001; Rice and Cragg, 2004; Britt and McGehee, 2008). Reverse transport via the dopamine transporter could also generate extracellular dopamine (Falkenburger et al., 2001). Here, we investigate the origin of dopamine transients in the NAc shell, a region that exhibits dopamine transients in animals at rest (Wightman et al., 2007), following pharmacological manipulation (Stuber et 
al., 2005; Cheer et al., 2007b), and in response to cues that predict reward (Phillips et al., 2003a; Roitman et al., 2004; Stuber et al., 2005; Cheer et al., 2007a; Owesson-White et al., 2008). Intra-VTA microinfusion of neuronal firing inhibitors establishes that dopamine transients in the NAc shell require ongoing phasic activity in the VTA.

\section{Materials and Methods \\ Electrodes}

Glass-encased, carbon-fiber microelectrodes were constructed as previously described with T-650 carbon fiber (Phillips et al., 2003b). The reference electrodes were chloridized silver wires $(0.5 \mathrm{~mm}$ diameter, Sigma-Aldrich) in $0.1 \mathrm{~N} \mathrm{HCl}$. All potentials reported are versus $\mathrm{Ag} / \mathrm{AgCl}$.

\section{Animals and surgery}

Male Sprague Dawley rats ( $n=22$; Charles River Laboratories; 250-350 g) some of which were implanted with a jugular vein catheter $(n=11)$ were individually housed on a 12:12 h light cycle with ad libitum access to food and water. Rats were anesthetized with ketamine hydrochloride $(100 \mathrm{mg} / \mathrm{kg}$, i.p.) and xylazine hydrochloride $(20 \mathrm{mg} / \mathrm{kg}$, i.p.) and stereotaxic surgeries were performed as described previously (Phillips et al., 2003b). The $\mathrm{Ag} / \mathrm{AgCl}$ reference electrode was placed in the forebrain, and a guide cannula (Bioanalytical Systems) was positioned above the contralateral NAc ( $1.7 \mathrm{~mm}$ anterior, $0.8 \mathrm{~mm}$ lateral, $2.5 \mathrm{~mm}$ ventral relative to bregma). A combination bipolar stimulating electrode/steel guide cannula (26 gauge; Plastics One) was implanted unilaterally into the VTA at a $6^{\circ}$ angle toward the midline to avoid the midline sinus $(5.4 \mathrm{~mm}$ posterior, $1.2 \mathrm{~mm}$ lateral, $7.8 \mathrm{~mm}$ ventral relative to bregma). The components were permanently affixed with dental cement. The animals recovered for $3 \mathrm{~d}$. All procedures were performed in accordance with the University of North Carolina Animal Care and Use Committee.

\section{Data acquisition}

The cyclic voltammetric waveform was generated and the resulting signal was collected using LabVIEW (National Instruments) and a multifunction data acquisition board (PCI-6052E, National Instruments). PCI6711E and PCI-6601 (National Instruments) boards were used to synchronize waveform acquisition, data collection, and stimulation delivery. Waveform processing and current transduction used custom-built instrumentation (University of North Carolina, Department of Chemistry Electronics Facility).

\section{Recording sessions}

A fresh carbon-fiber microelectrode was lowered into the NAc. The electrodes were connected to a head-mounted amplifier attached to a commutator (Crist Instrument Company). Electrodes were conditioned at 60 $\mathrm{Hz}$ for 15 min with a triangular waveform $(-0.4 \mathrm{~V}$ to $1.3 \mathrm{~V}$ vs Ag/ $\mathrm{AgCl}$, $400 \mathrm{~V} / \mathrm{s}$ ), followed by $15 \mathrm{~min}$ of cycling at $10 \mathrm{~Hz}$. The microelectrode position was optimized by monitoring naturally occurring and electrically evoked (biphasic, $2 \mathrm{~ms} /$ phase, 24 pulses, $60 \mathrm{~Hz}, 125 \mu \mathrm{A}$ ) dopamine release. All data included in this work were from subjects whose electrically evoked dopamine release exhibited a signal-to-noise ratio of at least 30. Stimulated dopamine release was evoked at the end of each session to ensure neuronal viability, and the electrode response was calibrated in vitro. A separate set of animals exhibited naturally occurring dopamine transients but minimal or no stimulated release, suggesting a surgical misplacement of the combination bipolar stimulating electrode/steel guide microinjection cannula in the VTA. These were used as misplacement controls. Drugs (Sigma Aldrich) were administered with a syringe pump (Kent Scientific Corporation, $0.5 \mu \mathrm{l}$ for $60 \mathrm{~s}$ ) unilaterally via an infusion cannulae (33 gauge) inserted into the implanted guide.

Experiment 1. Experiments consisted of 2 min of baseline collection, 4 min of recording during and after microinfusion, and an electrical stimulation that evoked dopamine release $(n=6)$. The first microinfusion into the VTA consisted of saline $(0.9 \%)$, and the process was repeated 1 hour later with microinfusion of lidocaine $(350 \mathrm{nmol} / 0.5 \mu \mathrm{l}$, dissolved in sterile saline; $\mathrm{pH}$ 6). On the next day, a similar experiment was done with these animals to evaluate NMDA receptor effects. Microinfusions of saline into the VTA were followed 1 hour later by microinfusion of NMDA
$(0.2 \mathrm{nmol})$ or $( \pm)$-amino,5-phosphopentanoic acid (AP-5; $5 \mathrm{nmol}$ ) (dissolved in $0.5 \mu \mathrm{l}$ of sterile saline), randomly selected. Two hours later the other NMDA active compound was microinfused in the same way. Values were expressed as a ratio of postinfusion to preinfusion measurements. The onset of behavioral activation served as the initial time for the frequency measurement following NMDA or AP-5 microinfusion.

Experiment 2. After 2 min of baseline collection saline was microinfused into the VTA $(n=11)$. Thirty seconds into the microinfusion the animal received a computer-controlled, $3.0 \mathrm{mg} / \mathrm{kg}$ (i.v.) cocaine administration and recording continued for $90 \mathrm{~s}$. The microinfusion needle was then removed. Following a $2 \mathrm{~h}$ rest period, the experiment was repeated with a second $0.5 \mu \mathrm{l}$ of microinfusion of saline $(n=5)$ or lidocaine $(n=$ $6,350 \mathrm{nmol} / 0.5 \mu \mathrm{l}$, dissolved in saline; $\mathrm{pH}$ 6) and an identical systemic cocaine administration. On the next day, a similar experiment was done with the saline control animals to evaluate the effects of NMDA receptors on the cocaine-elicited dopamine release. The first part of the experiment was identical to that done on the previous day. The second part of the experiment (following the $2 \mathrm{~h}$ rest period) consisted of an intra-VTA microinfusion of AP-5 ( $5 \mathrm{nmol}$, dissolved in $0.5 \mu \mathrm{l}$ of sterile saline), paired with the systemic cocaine administration

Experiment 3. Rats $(n=5)$ were trained to perform intracranial selfstimulation (ICSS) on an FR1 reinforcement schedule as described previously (Owesson-White et al., 2008). The stimulation current was selected to optimize operant responding $(100-150 \mu \mathrm{A}, 60 \mathrm{~Hz}, 24$ biphasic pulses, $2 \mathrm{~ms} /$ phase). Initially, the lever was continuously extended and the rats pressed freely. Once criterion responding was achieved (30 consecutive presses), the lever was retracted. Rats were then trained to perform ICSS on an FR1, variable time-out reinforcement schedule. Lever extension was accompanied by simultaneous presentation of an audiovisual cue $(67 \mathrm{~dB}, 1 \mathrm{kHz})$ tone coupled with a change in the lighting of the experimental chamber) for the first 50 trials. The audiovisual cue was then set to precede lever extension by $2 \mathrm{~s}$ for the next 150 trials (OwessonWhite et al., 2008) with a random time-out between trials (5-25 s). This paradigm was used for the recording session.

Following training, a carbon-fiber microelectrode was lowered into the NAc and an optimal recording site was found as described above. Animals were allowed to resume operant responding for ICSS. Once a reproducible, cue-evoked increase in dopamine was detected the behavioral session was briefly stopped and saline $(0.9 \%, 0.5 \mu \mathrm{l})$ was microinfused into the VTA over $60 \mathrm{~s}$. The needle was removed $60 \mathrm{~s}$ after the end of the infusion, and the behavioral session resumed for 50 trials. Next, AP-5 ( $5 \mathrm{nmol}, 0.5 \mu \mathrm{l}$ ) was microinfused in an identical manner.

\section{Data analysis}

Background subtraction and digital filtering were done with locally written programs. A nonlinear color scale was used to represent the current (Wightman et al., 2007). Substances were resolved with principal component regression using MATLAB (The MathWorks) (Heien et al., 2005). Dopamine concentration transients were events with a signal-tonoise ratio greater than five, and were characterized with Mini Analysis Software (Synaptosoft).

\section{Statistical analysis}

Two-tailed paired Student's $t$ tests were used to determine statistical differences in all experiments except in experiment 3, where dopamine fluctuations were analyzed using a one-way ANOVA with Tukey's post hoc test for repeated measures. Statistical significance was designated at $p<0.05$. Statistical analyses were performed using GraphPad Prism 4 Software Version 4.03 for Windows (Graphpad Software).

\section{Histology}

Animals were anesthetized with sodium urethane $\left(2 \mathrm{~g} \mathrm{~kg}^{-1}\right.$, i.p.). NAc recording locations were marked via an electrical lesion. $0.5 \mu \mathrm{l}$ of a $2 \%$ Chicago Sky Blue solution was microinfused into the VTA. Animals were transcardially perfused with saline followed by $10 \%$ formalin. Brains were removed, frozen, coronally sectioned at $40 \mu \mathrm{m}$, stained with thionin and visualized under a microscope. 


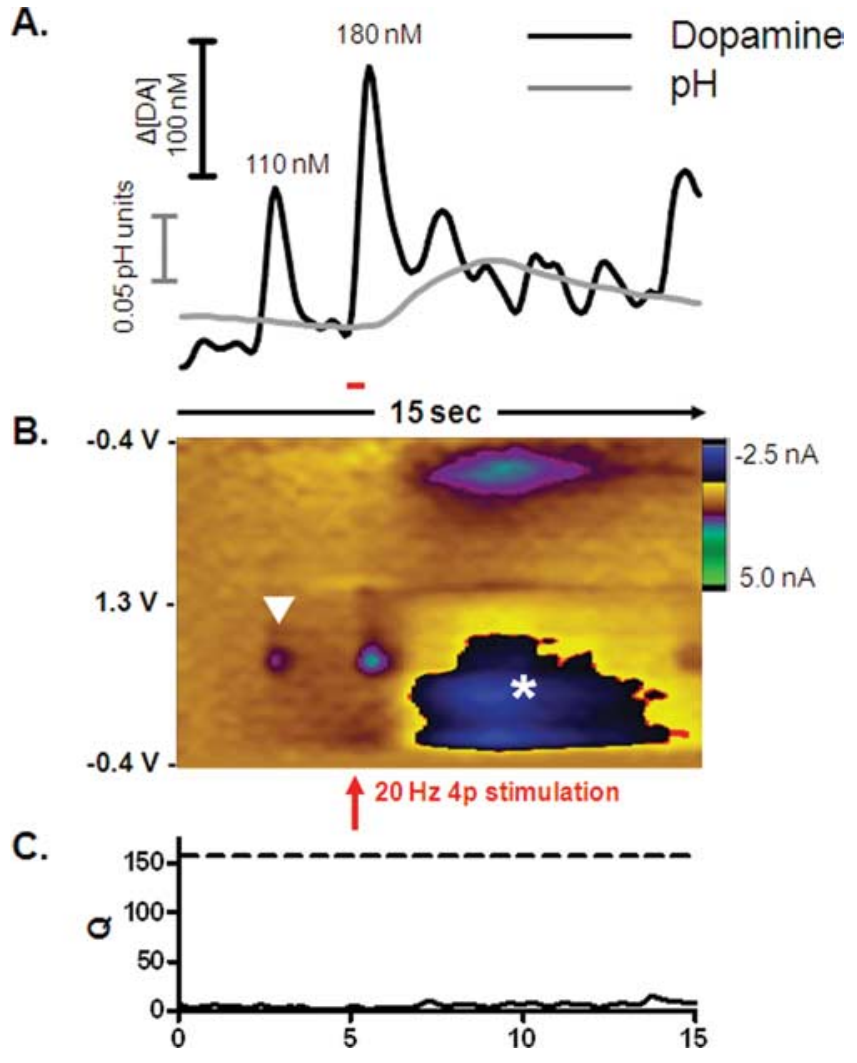

Figure 1. Voltammetric recording from an awake rat showing both naturally occurring (indicated with an inverted white triangle) and electrically evoked (arrow) dopamine release, and a pH shift (white asterisk). $\boldsymbol{A}$, Dopamine concentration changes and $\mathrm{pH}$ shift extracted from the voltammetric data using principal component analysis. $\boldsymbol{B}$, The color plot contains 150 background-subtracted cyclic voltammograms recorded over $15 \mathrm{~s}$. The ordinate is the potential applied to the carbon fiber electrode, the abscissa is time, and the current is depicted in false color. 4 p, Four pulse. C, The residual shows the principal components describe the data well. The dashed line is the threshold for noise predicted by the principal components.

\section{Results}

\section{Dopamine signals in the NAc shell}

Transient changes in dopamine concentration that occur following electrical stimulation of the VTA, and in absence of such a stimulation, can be measured using fast-scan cyclic voltammetry (Wightman et al., 2007). Figure 1 shows an example of voltammetric recordings obtained in the NAc shell of a resting, awake rat. At this recording site, frequent dopamine transients were observed that resemble dopamine release evoked by a four pulse, $20 \mathrm{~Hz}$ stimulation of the VTA (Fig. 1A,B). Principal component analysis with a training set made up of representative, background-subtracted cyclic voltammograms for dopamine and $\mathrm{pH}$ was used to extract the data from the color plot shown. The low residual (Fig. 1C) shows that the retained principal components describe the data well. The current fluctuations due to dopamine release are evident on the positive portion of the voltage scan at the potential where dopamine is oxidized $(\sim 0.6 \mathrm{~V}$ vs $\mathrm{Ag} / \mathrm{AgCl}$ ). Here, both naturally occurring (indicated by the inverted white triangle) and electrically evoked (red arrow) dopamine fluctuations are evident in the area surrounding the sensor, as well as a delayed and longer-lasting basic $\mathrm{pH}$ shift (white asterisk). The current fluctuation due to the $\mathrm{pH}$ shift is evident as a blue patch spanning $\sim-0.3 \mathrm{~V}$ to $+0.3 \mathrm{~V}$. pH shifts are typically seen after electrical stimulation of dopaminergic neurons (Cheer et al., 2006).

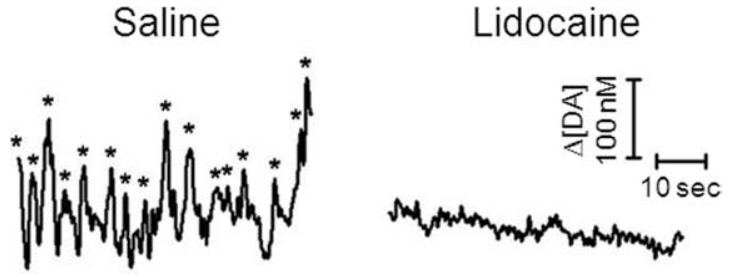

Figure 2. Dopamine transients in the NAc shell of an awake rat are suppressed or enhanced by select agents microinfused into the VTA (experiment 1). Representative dopamine signals after microinfusion of saline (left) and after microinfusion of lidocaine ( $350 \mathrm{nmol}$, right). Dopamine transients (with a signal-to-noise ratio $>5$, asterisks) are eliminated after microinfusion of lidocaine. Dopamine concentration changes were extracted from background-subtracted voltammograms.

Experiment 1: dopamine signaling in the NAc shell is dependent on neuronal activity in the VTA

After the electrode was positioned at a site where transients occurred and dopamine was electrically elicited, we assessed the effects of inactivation of the VTA on these signals. When the sodium channel blocker lidocaine was microinfused into the VTA $(350 \mathrm{nmol})$, both electrically evoked release $(p<0.05)$ and naturally occurring dopamine transients $(p<0.001)$ were significantly attenuated relative to their values following saline infusions. Lidocaine eliminates dopamine fluctuations as shown in a representative location in Figure 2, and the averaged effects are quantified and reported as ratios in Table 1. Intra-VTA lidocaine also reduced the electrically evoked, basic $\mathrm{pH}$ shifts in all animals tested (Table $1, p<0.05$ ). In the absence of electrical stimulation, $\mathrm{pH}$ shifts are less obvious and were not quantitated further. Dopamine and $\mathrm{pH}$ signals recovered in 1-2 $\mathrm{h}$ (data not shown). In a separate set of animals $(n=3)$ that did not exhibit electrically stimulated release and were thus used as misplacement controls, the effects of lidocaine microinfusion on naturally occurring dopamine transients were not significantly different from saline control (data not shown).

To investigate whether NMDA receptors in the VTA modulate the occurrence of dopamine transients in the NAc, we applied NMDA receptor-specific agents to the VTA. Local administration of NMDA into the VTA induces locomotor activity; thus we used doses shown to be most effective in generating locomotion to ensure an effective dose (Cornish et al., 2001; Ikemoto, 2004). In Figure $3 A$, four transients (indicated by asterisk) occurred during the $60 \mathrm{~s}$ interval shown before intra-VTA microinfusion. Following treatment with the selective NMDA receptor antagonist AP-5 (5 nmol, right panel) dopamine transients were abolished. The recording shown in Figure $3 B$ shows data collected from the same animal $2 \mathrm{~h}$ later. Three dopamine transients are evident before intra-VTA microinfusion (left), and 9 dopamine transients are evident immediately following the microinfusion of NMDA (right, $0.2 \mathrm{nmol}$ ). Figure $3 C$ quantifies these effects for all animals following microinfusion of saline $(n=6), \operatorname{AP}-5(n=$ $6)$, or NMDA $(n=5)$. The frequency of transients was unchanged by saline infusions. In contrast, AP- 5 significantly decreased the frequency of dopamine transients $(p<0.05)$, whereas the trend following NMDA was an increase in transients that did not achieve statistical significance. For both drugs, the neurochemical and behavioral effects were temporally coincident, with the peak effects lasting for 2 min before neurochemical rebound (data not shown). In the misplacement control subjects $(n=3)$, the effects of AP-5 or NMDA microinfusion on naturally occurring dopamine transients or behavior were not significantly different from saline control (data not shown). 
Experiment 2: NMDA receptors in the VTA regulate tonic and phasic dopamine fluctuations elicited by cocaine

A carbon fiber electrode was positioned in the NAc shell at a site that exhibited both naturally occurring dopamine transients occurring at $>1$ per min and electrically evoked dopamine release. A 1 min microinfusion of saline vehicle was administered, and thirty seconds later cocaine was administered intravenously at a dose $(3 \mathrm{mg} / \mathrm{kg})$ demonstrated previously to have robust effects both on dopamine extracellular concentrations and behavior (Di Chiara and Imperato, 1988; Heien et al., 2005).

Administration of cocaine caused a gradual increase in extracellular dopamine concentration in the NAc that appeared to plateau during the $90 \mathrm{~s}$ observation time with superimposed phasic dopamine transients. An example is shown in Figure $4 A$ (gray); it resembles that reported for an intravenous cocaine injection without an intra-VTA saline microinfusion (Heien et al., 2005). The increase in frequency and amplitude of dopamine transients is termed the phasic response while the more gradual increase in dopamine concentration is termed the tonic response. One hour later, a second intraVTA saline microinfusion was administered followed $30 \mathrm{~s}$ later by a second cocaine administration $(n=5)$. Dopamine concentration changes due to this second cocaine challenge (Fig. $4 A$, black) are the same as those following the initial intravenous cocaine injection. Figure 4, $B$ and $C$, shows representative examples using the same protocol but the second VTA microinfusion was of either lidocaine $(n=6,350 \mathrm{nmol})$ (Fig. $4 B$ ) or AP-5 ( $n=5,5 \mathrm{nmol}$ ) (Fig. $4 C)$. In both cases the dopamine responses were attenuated. In a separate set of misplacement control subjects $(n=2)$, the effects of AP- 5 or lidocaine microinfusion on the cocaine-evoked dopamine response were not significantly different from saline control (data not shown).

The tonic increase in dopamine concentration $\left([\mathrm{DA}]_{\mathrm{T}}\right)$ was quantified as the average cocaine-induced increase in concentration during a $10 \mathrm{~s}$ epoch at the end of the sampling period (50-60 s after cocaine administration) relative to that measured in the $10 \mathrm{~s}$ epoch immediately before cocaine (Fig. 4, epochs boxed in gray, left). Phasic fluctuations in dopamine concentration were quantitated as the number of dopamine transients measured during the second epoch. The averaged tonic and phasic dopamine responses for all animals ( $n=5$ saline, $n=5 \mathrm{AP}-5, n=6$ lidocaine) are shown in Table 2 . Both types of cocaine-induced dopamine responses were significantly diminished by intra-VTA microinfusion of lidocaine or AP-5, but not saline.

Experiment 3: NMDA receptors in the VTA regulate cueinduced phasic dopamine fluctuations

We previously reported enhanced rapid dopamine signaling relative to cues during ICSS (Owesson-White et al., 2008). Rats were A. AP-5

B. NMDA
Table 1. Effects of VTA inactivation on spontaneous and stimulated responses in the NAc shell (experiment 1)

\begin{tabular}{llll}
\hline Treatment & Stimulated DA & Stimulated pH & Relative frequency of spontaneous DA \\
\hline Saline & $1.12 \pm 0.28$ & $0.92 \pm 0.09$ & $0.94 \pm 0.07$ \\
Lidocaine & $0.01 \pm 0.01^{*}$ & $0.15 \pm 0.07^{*}$ & $0.08 \pm 0.04^{* * *}$ \\
\hline
\end{tabular}

Average effects of intra-VTA saline or lidocaine ( $n=5$ for each microinfusion) on electrically stimulated dopamine release, electrically stimulated basic $\mathrm{pH}$ shifts, and relative frequency of naturally occurring dopamine transients (right, averaged over 2 min epochs). Values are expressed as a ratio of postinfusion
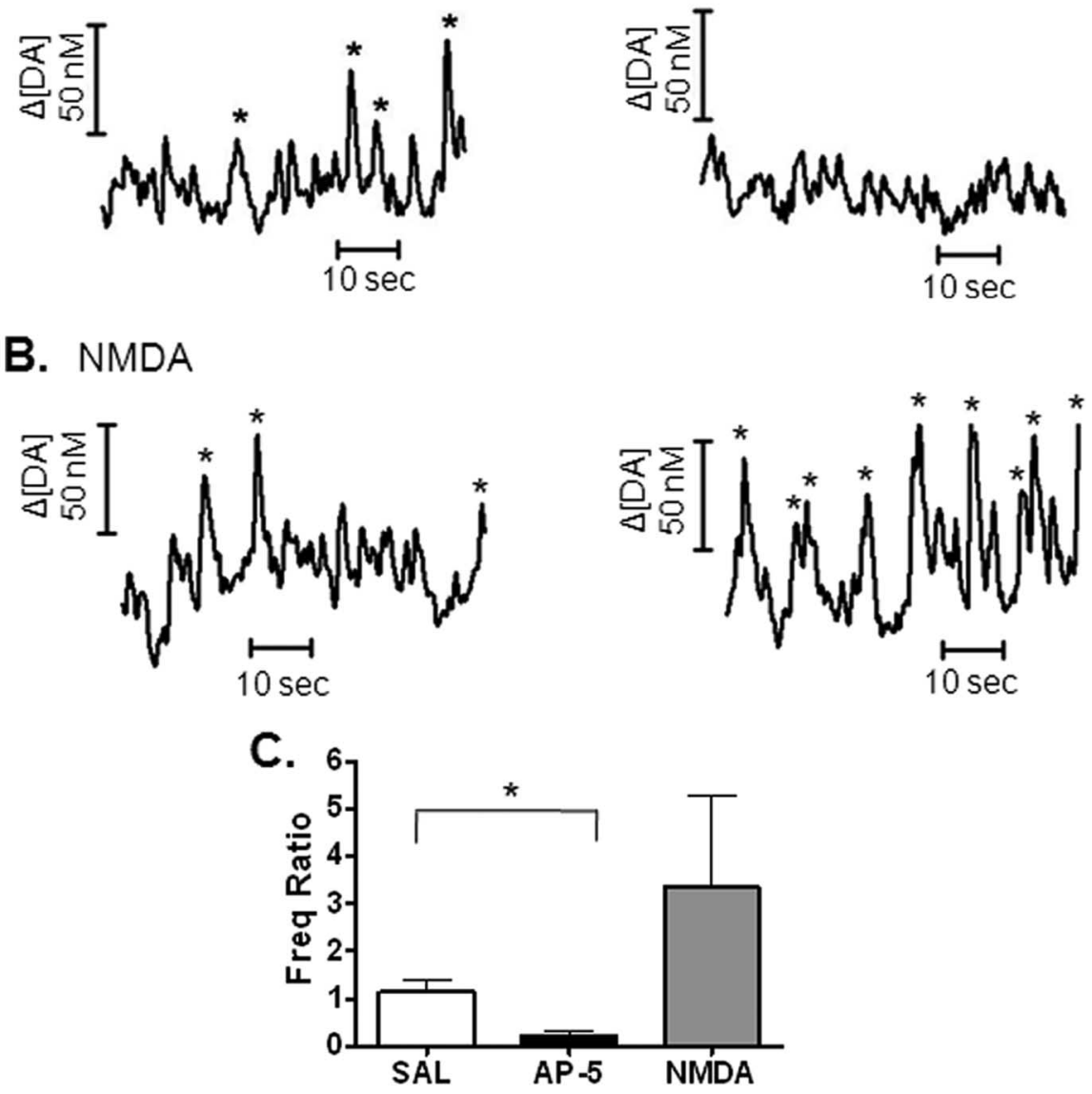

Figure 3. Phasic dopamine signaling is modulated by NMDA receptor-dependent agents in the VTA (experiment 1). $\boldsymbol{A}, \boldsymbol{B}$, Representative voltammetric data collected in the NAc shell of an awake animal at rest before (left) and immediately after (right) an intra-VTA microinfusion. Dopamine fluctuations are indicated by the asterisks, and are attenuated by microinfusion of AP-5 ( $\boldsymbol{A})$ Average dopamine transient frequency ratio (measured over $2 \mathrm{~min}$ ) before and after microinfusions of saline $(n=6), \mathrm{AP}-5(5$ $\left.\mathrm{nmol}, n=6,{ }^{*} p<0.05\right)$, and NMDA $(0.2 \mathrm{nmol}, n=5)$.

trained to depress a lever to deliver an electrical stimulation (60 $\mathrm{Hz}, 24$ biphasic pulses, $125 \mu \mathrm{A}$ each phase) to their VTA. Lever extension was preceded by $2 \mathrm{~s}$ with an audio-visual cue. Consistent with our prior reports, presentation of the cue predicting ICSS availability elicits a time-locked, transient increase in extracellular dopamine concentration in the NAc shell that precedes the electrically stimulated dopamine response (Fig. 5A). IntraVTA microinfusion of saline did not significantly alter the cueevoked dopamine release (Fig. 5A, left) while intra-VTA microinfusion of AP-5 dramatically decreased it (Fig. 5A, right). Interestingly, intra-VTA application of AP-5 also decreased electrically stimulated dopamine release in the NAc (Fig. $5 A$, right). Across all animals $(n=5)$, intra-VTA microinfusion of AP-5 produced a significant attenuation $(p<0.001)$ (Fig. $5 B)$ in the cue-evoked response that exhibited postinfusion recovery and a significant attenuation in stimulated release $(p<0.001)$ (data 
A.

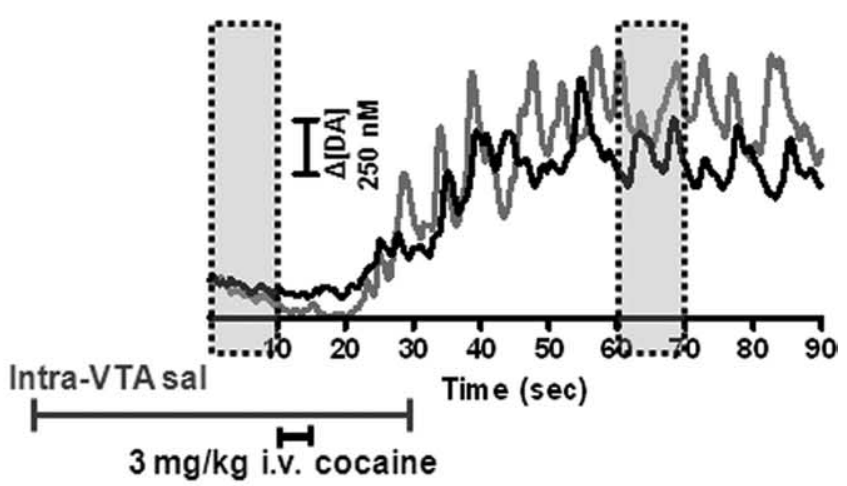

B.
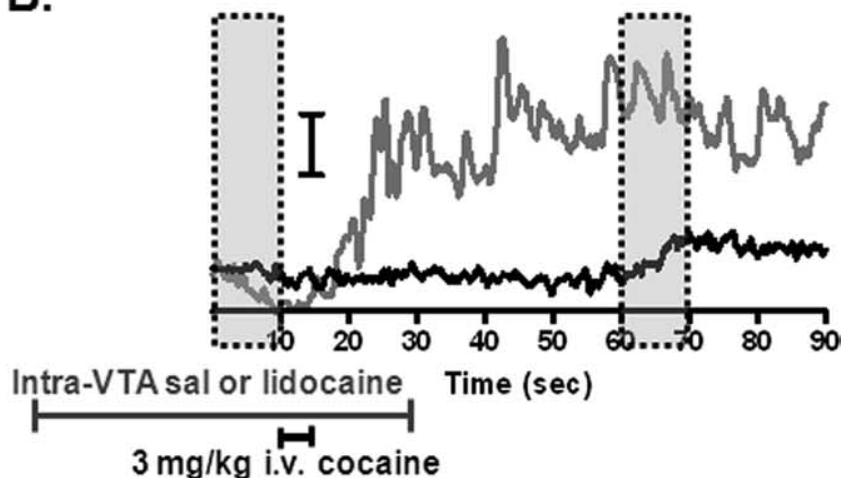

C.

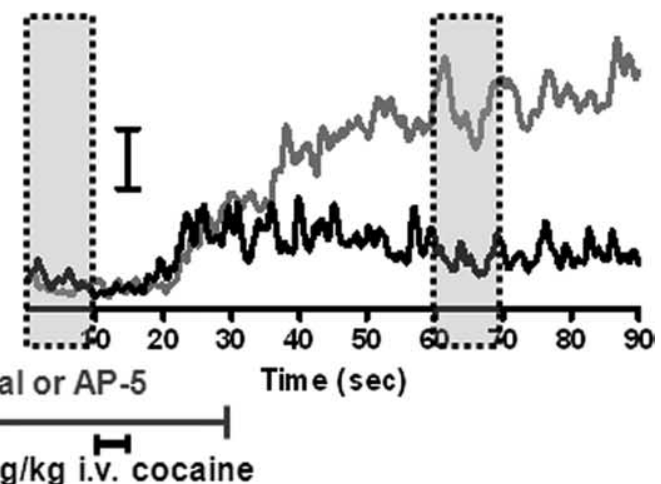

Figure 4. NMDA receptors in the VTA regulate phasic and tonic dopamine in the NAc shell elicited by intravenous cocaine administration (experiment 2). $\boldsymbol{A}-\boldsymbol{C}$, Each panel contains two superimposed concentration traces collected in a single animal. The animals first received an intra-VTA saline microinfusion during which cocaine was administered intravenously (gray). A second systemic cocaine administration was given $2 \mathrm{~h}$ later while saline $(n=5)(A)$, lidocaine $(350 \mathrm{nmol}, n=5)(\boldsymbol{B})$, or AP-5 ( $5 \mathrm{nmol}, n=6)(\boldsymbol{C})$ was infused into the VTA (black). Scale bar is the same in all traces.

not shown). The average latency to lever press following lever extension was significantly increased after microinfusion of AP-5 relative to saline values $(p<0.01)$ (Table 3 ).

\section{Histology}

Histological examination of electrode placements in select animals revealed that recordings were made in the NAc shell; see Figure $6 A$ for details. For visualization of the region of the VTA affected by microinfusion, $0.5 \mu \mathrm{l}$ of a $2 \%$ Chicago Sky Blue solution was microinfused immediately before fixation. The location
Table 2. NMDA receptors in the VTA regulate phasic and tonic dopamine in the NAC shell elicited by intravenous cocaine administration (experiment 2)

\begin{tabular}{lcl}
\hline Treatment & {$[\mathrm{DA}]_{\mathrm{T}}(\mathrm{nm})$} & Transient count/10 S \\
\hline Saline 1 & $396 \pm 140$ & $2.5 \pm 0.6$ \\
Saline 2 & $262 \pm 61$ & $2.3 \pm 0.9$ \\
Saline & $266 \pm 73$ & $3.6 \pm 0.6$ \\
Lidocaine & $36 \pm 27^{*}$ & $0.6 \pm 0.4^{* *}$ \\
Saline & $371 \pm 58$ & $2.6 \pm 0.5$ \\
AP-5 & $74 \pm 59^{*}$ & $1.0 \pm 0.4^{*}$ \\
\hline
\end{tabular}

Intra-VTA microinfusion of AP-5 or lidocaine significantly decreased both the average dopamine concentration increase $\left([D A]_{T}\right)$ and the number of phasic events elicited by cocaine compared with microinfusion of saline $\left({ }^{*} p<\right.$ $0.05,{ }^{* *} p<0.01$, Student's $t$ test).

A. Saline

AP-5
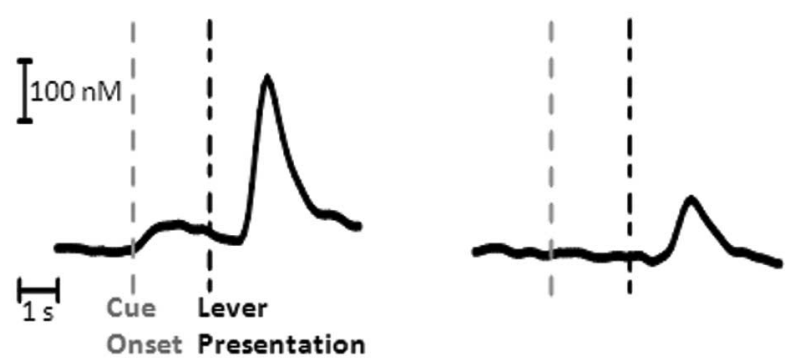

B.

Cue-Evoked Dopamine Release

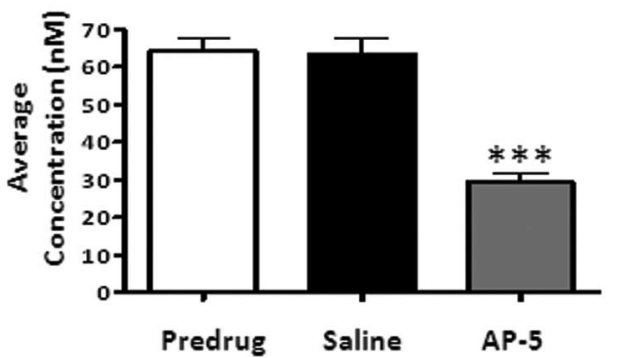

Figure 5. NMDA receptors in the VTA regulate phasic dopamine elicited by rewardpredictive cues (experiment 3 ). $A$, Representative dopamine concentration trace after microinfusion of saline (left) is attenuated after AP-5 microinfusion (right). $\boldsymbol{B}$, Average cue-evoked dopamine concentration changes for 50 trials, $n=5$ rats. Intra-VTA microinfusion of AP-5, but not saline, significantly decreased the dopamine concentration change elicited by the cue $\left({ }^{* * *} p<0.001\right)$.

Table 3. Average latency to press for ICS (experiment 3)

\begin{tabular}{ll}
\hline Treatment & Latency \\
\hline Saline & $0.89 \pm 0.18$ \\
AP-5 & $1.89 \pm 0.38^{* *}$
\end{tabular}

The average latency to lever press was significantly increased by intra-VTA AP- $5\left({ }^{* *} p<0.01\right.$, Student's $t$ test) but not saline. Values are expressed as a ratio of postinfusion to preinfusion measurements.

of each cannula tip is shown in Figure $6 \mathrm{~B}$. Subjects included in this work $(n=14$, black) showed dye covering $\sim 70 \%$ of the VTA, defined as the paranigral, the parainterfascicular, the parabrachial pigmented nuclei and the rostral VTA (Paxinos and Watson, 2005). In misplacement control subjects that did not exhibit stimulated dopamine release ( $n=5$, gray), dye covered less than $\sim 10 \%$ of the VTA.

\section{Discussion}

Using fast-scan cyclic voltammetry at carbon fiber microelectrodes in freely moving rats, subsecond, dopamine- 
concentration fluctuations (transients) can be detected in select locations of the NAc (Wightman et al., 2007). Dopamine transients become more pronounced following administration of drugs of abuse (Cheer et al., 2007b), and they become time locked to cues that predict reward availability (Phillips et al., 2003a; Roitman et al., 2004; Stuber et al., 2005; Day et al., 2007; Owesson-White et al., 2008). Here, we establish that dopamine transients observed during these three distinct conditions depend on neuronal activity in the VTA. Although factors such as neuronal firing history and presynaptic mechanisms may modulate synaptic dopamine overflow, this work confirms that NMDA receptor-mediated firing of dopamine neurons in the VTA is a major factor underlying rapid dopamine neurotransmission in the NAc shell.

We previously hypothesized that dopamine transients arise from phasic firing of dopaminergic neurons (Wightman et al., 2007). Modeling of dopamine terminal activity during phasic firing predicts increased extracellular dopamine (Arbuthnott and Wickens, 2007) due to a decreased time between action pulses that allows less time for uptake (Venton et al., 2003), consistent with the results of Figure 1. Such an accumulation of dopamine enables activation of both low affinity as well as high affinity dopamine receptors (Richfield et al., 1989), and suggests functionally distinct roles arising from tonic and phasic firing modes. Further support that dopamine transients arise from phasic firing comes from the similarity between the rate of transients observed and the rate of action potential bursts exhibited by the majority of dopaminergic neurons in the VTA of ambulant rats (Hyland et al., 2002). Consistent with this evidence, naturally occurring dopamine transients, as well as electrically stimulated release, were abolished by nonspecific inactivation of the VTA via lidocaine microinfusion in experiment 1 (Fig. 2, Table 1). Furthermore, the $\mathrm{pH}$ changes that are evoked by electrical stimulation, and are a consequence of changes in local blood flow and metabolism (Cheer et al., 2006), were also abolished by microinfusions of lidocaine (Fig. 2, Table 1). pH changes occur independently of dopamine release (Cheer et al., 2006); however, the present data suggests that they also originate from presynaptic activity of VTA neurons that project to the NAc.

As reviewed by Fields et al. (2007), excitatory projections to the VTA include glutamatergic inputs from the lateral hypothalamus (LH) (Rosin et al., 2003), bed nucleus of the stria terminalis (Georges and Aston-Jones, 2002), the superior colliculus (Geisler and Zahm, 2005) and a large excitatory input from the prefrontal cortex (PFC) (Sesack and Pickel, 1992). Additionally, two groups of mesopontine tegmental area neurons provide a large excitatory input to the VTA: the pedunculopontine tegmental nucleus (PPTg) and the laterodorsal tegmental nucleus (LDT) (Semba and Fibiger, 1992). The NMDA receptors located on dopaminergic neurons are major targets of these inputs, and electrophysiological studies have shown that application of NMDA into the VTA produces phasic firing in putative dopamine neurons (Johnson et al., 1992; Chergui et al., 1993). In vitro studies in VTA slices have shown that the non-NMDA agonists kainate or quisqualate do not induce bursts (Johnson et al., 1992), and have also shown that application of NMDA antagonists block glutamate- induced firing rate increases (Wang and French, 1993). Iontophoretic ejections of NMDA receptor antagonists into the VTA potently regularized the discharge pattern of phasic firing cells (Overton and Clark, 1992; Chergui et al., 1993). However similar ejections of CNQX, a competitive AMPA/kainate glutamate receptor antagonist, were unable to affect the firing pattern (Chergui et al., 1993). The effects of microinfusion of NMDA were compared with those induced by non-NMDA excitatory agonists. While all agonists increased the firing rate of putative dopaminergic neurons; only NMDA evoked a phasic firing pattern (Suaud-Chagny et al., 1992; Chergui et al., 1993). Using differential pulse amperometry in anesthetized rats treated with pargyline, NMDA was shown to be twice as potent as quisqualate at evoking NAc dopamine release (Suaud-Chagny et al., 1992).

Since the control of bursting activity by NMDA receptors is well documented, we microinfused the NMDA antagonist, AP-5 into the VTA. Like lidocaine, AP-5 inhibited the occurrence of dopamine transients (Fig. 3). This result is consistent with prior microdialysis studies in freely moving animals that showed a decrease in extracellular dopamine levels following intra-VTA administration of AP-5 (Karreman et al., 1996; Kretschmer, 1999). The diminished transient frequency after AP-5 microinfusions demonstrates that NMDA receptors are occupied with endogenous ligand in freely moving animals, and the lack of significance in our NMDA microinfusion results may indicate that further activity is difficult to promote with NMDA microinfusion alone. Indeed, only small dopamine increases were found with microdialysis using similar doses of NMDA (Karreman et al., 1996; Kretschmer, 1999).

Dopamine transients are significantly enhanced when the dopamine transporter is inhibited (Stuber et al., 2005; Cheer et al., 2007b; Aragona et al., 2008). Specifically, intravenous injection of cocaine increases the transient frequency in the NAc and also causes a gradual increase in extracellular dopamine (Heien et al., 2005). The gradual increase is consistent with uptake inhibition accompanying continued tonic firing (Venton et al., 2003). While it has long been known that dopamine release by cocaine requires neuronal action potentials (Nomikos et al., 1990), the cocaine-induced increase in rapid dopamine transients was not originally anticipated because cocaine tends to decrease the firing rate of VTA neurons (Einhorn et al., 1988), presumably due to $\mathrm{D}_{2}$ 
autoreceptor-mediated inhibition of firing (Bunney et al., 2001; Shi et al., 2004). The results of experiment 2 show that both tonic $\left([\mathrm{DA}]_{\mathrm{T}}\right)$ and phasic (transients) cocaine-induced increases in dopamine concentrations in the NAc shell are virtually eliminated with VTA inactivation by lidocaine (Fig. $4 B$, Table 2). Thus, ongoing firing of VTA neurons is necessary for cocaine to elevate dopamine concentrations in the NAc. Similarly, NMDAreceptor blockade attenuated the effects of cocaine on dopamine concentrations, demonstrating that glutamatergic activation of the VTA is a necessary component of cocaine-induced dopamine changes in the NAc (Fig. 4C, Table 2). Indeed, it has been shown by microdialysis that acute cocaine administration elevates extracellular VTA glutamate (Kalivas and Duffy, 1995). Consistent with this, intra-VTA application of ionotropic glutamate receptor antagonists reduces the rewarding effects of cocaine (Harris and Aston-Jones, 2003; Sun et al., 2005; You et al., 2007). Even a single exposure to cocaine potentiates NMDA receptor function in the VTA (Schilström et al., 2006), and with repeated cocaine treatments or cocaine self-administration this effect may become even more prominent.

Like the burst firing of dopaminergic neurons (Schultz, 1998), dopamine transients in the NAc become time-locked to cues that predict reward availability in well trained animals (Phillips et al., 2003a; Roitman et al., 2004; Stuber et al., 2005; Cheer et al., 2007a; Day et al., 2007; Owesson-White et al., 2008). Furthermore, NMDA receptors in the VTA play a key role in the acquisition of reward-related learning (Zellner et al., 2008). Thus, experiment 3 examined whether cue-evoked dopamine signals and behavior during ICSS were altered by pharmacological inhibition of VTA phasic firing. Intra-VTA microinfusion of AP-5 produced a significant decrease in cue-evoked dopamine release in the NAc (Fig. 5A, B). At the same time the latency to lever press for ICSS was increased (Table 3 ). The NAc is thought to act as a limbicmotor interface, integrating information from limbic and cortical afferents and influencing goal-directed behavior via its efferent projections (Goto and Grace, 2005; Nicola et al., 2005). Thus, fluctuations in NAc dopamine are anticipated to influence behavioral output. The simultaneous attenuation of cue-induced dopamine transients and delayed lever pressing behavior caused by AP-5 microinfusion provide direct support for this hypothesis. The application of AP-5 to the VTA also significantly attenuated electrically stimulated dopamine release in the NAc, suggesting that electrically stimulated dopamine release is an indirect response resulting from glutamatergic innervation of the VTA. Indeed, direct activation of dopamine neurons is unlikely to occur with electrical stimulation to the cell bodies because they have thin, unmyelinated axons and exhibit high thresholds of activation (Ranck, 1975; Yeomans et al., 1988; Yeomans, 1989; Anderson et al., 1996; Nowak and Bullier, 1998).

Much of our knowledge of the role of dopamine has come from single-unit electrophysiological recordings. However, identification of VTA dopamine neurons by electrophysiological characteristics can be ambiguous (Margolis et al., 2006). Here we provide unequivocal confirmation that dopamine release in terminal fields follows the expectations of the classic electrophysiological studies. In the NAc shell, extracellular dopamine levels fall when phasic activity in the VTA is disrupted or when the VTA is inactivated. Even more intriguing, this relationship is maintained whether dopamine fluctuations in the NAc are spontaneous in animals at rest, pharmacologically induced by cocaine administration, or evoked by ICSS reward-predictive cues. This suggests that NMDA-dependent phasic firing of dopamine cells is a mechanism that is broadly operant and not solely associated with reward-related stimuli. Dopamine neurons are conditional output neurons capable of switching between tonic and phasic firing patterns (Floresco et al., 2003), and this work shows that activation of NMDA receptors is necessary to enable the switch. Further research into other neuronal mechanisms underlying phasic firing will increase our understanding of reward-related behaviors and disease states, including addiction.

\section{References}

Anderson RM, Fatigati MD, Rompré PP (1996) Estimates of the axonal refractory period of midbrain dopamine neurons: their relevance to brain stimulation reward. Brain Res 718:83-88.

Aragona BJ, Cleaveland NA, Stuber GD, Day JJ, Carelli RM, Wightman RM (2008) Preferential enhancement of dopamine transmission within the nucleus accumbens shell by cocaine is attributable to a direct increase in phasic dopamine release events. J Neurosci 28:8821-8831.

Arbuthnott GW, Wickens J (2007) Space, time and dopamine. Trends Neurosci 30:62-69.

Britt JP, McGehee DS (2008) Presynaptic opioid and nicotinic receptor modulation of dopamine overflow in the nucleus accumbens. J Neurosci 28:1672-1681.

Bunney EB, Appel SB, Brodie MS (2001) Electrophysiological effects of cocaethylene, cocaine, and ethanol on dopaminergic neurons of the ventral tegmental area. J Pharmacol Exp Ther 297:696-703.

Cheer JF, Wassum KM, Wightman RM (2006) Cannabinoid modulation of electrically evoked $\mathrm{pH}$ and oxygen transients in the nucleus accumbens of awake rats. J Neurochem 97:1145-1154.

Cheer JF, Aragona BJ, Heien ML, Seipel AT, Carelli RM, Wightman RM (2007a) Coordinated accumbal dopamine release and neural activity drive goal-directed behavior. Neuron 54:237-244.

Cheer JF, Wassum KM, Sombers LA, Heien ML, Ariansen JL, Aragona BJ, Phillips PE, Wightman RM (2007b) Phasic dopamine release evoked by abused substances requires cannabinoid receptor activation. J Neurosci 27:791-795.

Chergui K, Charléty PJ, Akaoka H, Saunier CF, Brunet JL, Buda M, Svensson TH, Chouvet G (1993) Tonic activation of NMDA receptors causes spontaneous burst discharge of rat midbrain dopamine neurons in vivo. Eur J Neurosci 5:137-144.

Cornish JL, Nakamura M, Kalivas PW (2001) Dopamine-independent locomotion following blockade of N-methyl-D-aspartate receptors in the ventral tegmental area. J Pharmacol Exp Ther 298:226-233.

Day JJ, Roitman MF, Wightman RM, Carelli RM (2007) Associative learning mediates dynamic shifts in dopamine signaling in the nucleus accumbens. Nat Neurosci 10:1020-1028.

Di Chiara G, Imperato A (1988) Drugs abused by humans preferentially increase synaptic dopamine concentrations in the mesolimbic system of freely moving rats. Proc Natl Acad Sci U S A 85:5274-5278.

Einhorn LC, Johansen PA, White FJ (1988) Electrophysiological effects of cocaine in the mesoaccumbens dopamine system: studies in the ventral tegmental area. J Neurosci 8:100-112.

Everitt BJ, Robbins TW (2000) Second-order schedules of drug reinforcement in rats and monkeys: measurement of reinforcing efficacy and drugseeking behaviour. Psychopharmacology 153:17-30.

Falkenburger BH, Barstow KL, Mintz IM (2001) Dendrodendritic inhibition through reversal of dopamine transport. Science 293:2465-2470.

Fields HL, Hjelmstad GO, Margolis EB, Nicola SM (2007) Ventral tegmental area neurons in learned appetitive behavior and positive reinforcement. Annu Rev Neurosci 30:289-316.

Floresco SB, West AR, Ash B, Moore H, Grace AA (2003) Afferent modulation of dopamine neuron firing differentially regulates tonic and phasic dopamine transmission. Nat Neurosci 6:968-973.

Geisler S, Zahm DS (2005) Afferents of the ventral tegmental area in the rat-anatomical substratum for integrative functions. J Comp Neurol 490:270-294.

Georges F, Aston-Jones G (2002) Activation of ventral tegmental area cells by the bed nucleus of the stria terminalis: a novel excitatory amino acid input to midbrain dopamine neurons. J Neurosci 22:5173-5187.

Goto Y, Grace AA (2005) Dopaminergic modulation of limbic and cortical drive of nucleus accumbens in goal-directed behavior. Nat Neurosci 8:805-812.

Harris GC, Aston-Jones G (2003) Critical role for ventral tegmental gluta- 
mate in preference for a cocaine-conditioned environment. Neuropsychopharmacology 28:73-76.

Heien ML, Khan AS, Ariansen JL, Cheer JF, Phillips PE, Wassum KM, Wightman RM (2005) Real-time measurement of dopamine fluctuations after cocaine in the brain of behaving rats. Proc Natl Acad Sci U S A 102:10023-10028.

Howland JG, Taepavarapruk P, Phillips AG (2002) Glutamate receptordependent modulation of dopamine efflux in the nucleus accumbens by basolateral, but not central, nucleus of the amygdala in rats. J Neurosci 22:1137-1145.

Hyland BI, Reynolds JN, Hay J, Perk CG, Miller R (2002) Firing modes of midbrain dopamine cells in the freely moving rat. Neuroscience 114:475-492.

Ikemoto S (2004) Unconditional hyperactivity and transient reinforcing effects of NMDA administration into the ventral tegmental area in rats. Psychopharmacology 172:202-210.

Johnson SW, Seutin V, North RA (1992) Burst firing in dopamine neurons induced by $\mathrm{N}$-methyl-D-aspartate: role of electrogenic sodium pump. Science 258:665-667.

Kalivas PW, Duffy P (1995) D 1 receptors modulate glutamate transmission in the ventral tegmental area. J Neurosci 15:5379-5388.

Karreman M, Westerink BH, Moghaddam B (1996) Excitatory amino acid receptors in the ventral tegmental area regulate dopamine release in the ventral striatum. J Neurochem 67:601-607.

Kita JM, Parker LE, Phillips PE, Garris PA, Wightman RM (2007) Paradoxical modulation of short-term facilitation of dopamine release by dopamine autoreceptors. J Neurochem 102:1115-1124.

Kretschmer BD (1999) Modulation of the mesolimbic dopamine system by glutamate: role of NMDA receptors. J Neurochem 73:839-848.

Lodge DJ, Grace AA (2006) The hippocampus modulates dopamine neuron responsivity by regulating the intensity of phasic neuron activation. Neuropsychopharmacology 31:1356-1361.

Margolis EB, Lock H, Hjelmstad GO, Fields HL (2006) The ventral tegmental area revisited: is there an electrophysiological marker for dopaminergic neurons? J Physiol 577:907-924.

Montague PR, McClure SM, Baldwin PR, Phillips PE, Budygin EA, Stuber GD, Kilpatrick MR, Wightman RM (2004) Dynamic gain control of dopamine delivery in freely moving animals. J Neurosci 24:1754-1759.

Nicola SM, Taha SA, Kim SW, Fields HL (2005) Nucleus accumbens dopamine release is necessary and sufficient to promote the behavioral response to reward-predictive cues. Neuroscience 135:1025-1033.

Nomikos GG, Damsma G, Wenkstern D, Fibiger HC (1990) In vivo characterization of locally applied dopamine uptake inhibitors by striatal microdialysis. Synapse 6:106-112.

Nowak LG, Bullier J (1998) Axons, but not cell bodies, are activated by electrical stimulation in cortical gray matter. I. Evidence from chronaxie measurements. Exp Brain Res 118:477-488.

Overton P, Clark D (1992) Iontophoretically administered drugs acting at the N-methyl-D-aspartate receptor modulate burst firing in A9 dopamine neurons in the rat. Synapse 10:131-140.

Overton PG, Clark D (1997) Burst firing in midbrain dopaminergic neurons. Brain Res Brain Res Rev 25:312-334.

Owesson-White CA, Cheer JF, Beyene M, Carelli RM, Wightman RM (2008) Dynamic changes in accumbens dopamine correlate with learning during intracranial self-stimulation. Proc Natl Acad Sci U S A 105:11957-11962.

Paxinos G, Watson C (1997) The rat brain in stereotaxic coordinates, compact Ed 3. San Diego: Academic.

Paxinos G, Watson C (2005) The rat brain in stereotaxic coordinates, Ed 5. London: Elsevier Academic.

Phillips PE, Stuber GD, Heien ML, Wightman RM, Carelli RM (2003a) Subsecond dopamine release promotes cocaine seeking. Nature 422:614-618

Phillips PE, Robinson DL, Stuber GD, Carelli RM, Wightman RM (2003b) Real-time measurements of phasic changes in extracellular dopamine concentration in freely moving rats by fast-scan cyclic voltammetry. Methods Mol Med 79:443-464.

Ranck JB Jr (1975) Which elements are excited in electrical stimulation of mammalian central nervous system: a review. Brain Res 98:417-440.

Rice ME, Cragg SJ (2004) Nicotine amplifies reward-related dopamine signals in striatum. Nat Neurosci 7:583-584.
Richfield EK, Penney JB, Young AB (1989) Anatomical and affinity state comparisons between dopamine $\mathrm{D}_{1}$ and $\mathrm{D}_{2}$ receptors in the rat central nervous system. Neuroscience 30:767-777.

Robinson DL, Heien ML, Wightman RM (2002) Frequency of dopamine concentration transients increases in dorsal and ventral striatum of male rats during introduction of conspecifics. J Neurosci 22:10477-10486.

Roitman MF, Stuber GD, Phillips PE, Wightman RM, Carelli RM (2004) Dopamine operates as a subsecond modulator of food seeking. J Neurosci 24:1265-1271.

Rosin DL, Weston MC, Sevigny CP, Stornetta RL, Guyenet PG (2003) Hypothalamic orexin (hypocretin) neurons express vesicular glutamate transporters VGLUT1 or VGLUT2. J Comp Neurol 465:593-603.

Schilström B, Yaka R, Argilli E, Suvarna N, Schumann J, Chen BT, Carman M, Singh V, Mailliard WS, Ron D, Bonci A (2006) Cocaine enhances NMDA receptor-mediated currents in ventral tegmental area cells via dopamine $\mathrm{D}_{5}$ receptor-dependent redistribution of NMDA receptors. J Neurosci 26:8549-8558.

Schultz W (1998) Predictive reward signal of dopamine neurons. J Neurophysiol 80:1-27.

Schultz W, Dayan P, Montague PR (1997) A neural substrate of prediction and reward. Science 275:1593-1599.

Semba K, Fibiger HC (1992) Afferent connections of the laterodorsal and the pedunculopontine tegmental nuclei in the rat: a retro- and anterograde transport and immunohistochemical study. J Comp Neurol 323:387-410.

Sesack SR, Pickel VM (1992) Prefrontal cortical efferents in the rat synapse on unlabeled neuronal targets of catecholamine terminals in the nucleus accumbens septi and on dopamine neurons in the ventral tegmental area. J Comp Neurol 320:145-160.

Shi WX, Pun CL, Zhou Y (2004) Psychostimulants induce low-frequency oscillations in the firing activity of dopamine neurons. Neuropsychopharmacology 29:2160-2167.

Stuber GD, Wightman RM, Carelli RM (2005) Extinction of cocaine selfadministration reveals functionally and temporally distinct dopaminergic signals in the nucleus accumbens. Neuron 46:661-669.

Suaud-Chagny MF, Chergui K, Chouvet G, Gonon F (1992) Relationship between dopamine release in the rat nucleus accumbens and the discharge activity of dopaminergic neurons during local in vivo application of amino acids in the ventral tegmental area. Neuroscience 49:63-72.

Sun W, Akins CK, Mattingly AE, Rebec GV (2005) Ionotropic glutamate receptors in the ventral tegmental area regulate cocaine-seeking behavior in rats. Neuropsychopharmacology 30:2073-2081.

Venton BJ, Zhang H, Garris PA, Phillips PE, Sulzer D, Wightman RM (2003) Real-time decoding of dopamine concentration changes in the caudateputamen during tonic and phasic firing. J Neurochem 87:1284-1295.

Wang T, French ED (1993) L-glutamate excitation of A10 dopamine neurons is preferentially mediated by activation of NMDA receptors: extraand intracellular electrophysiological studies in brain slices. Brain Res 627:299-306.

Wightman RM, Heien ML, Wassum KM, Sombers LA, Aragona BJ, Khan AS, Ariansen JL, Cheer JF, Phillips PE, Carelli RM (2007) Dopamine release is heterogeneous within microenvironments of the rat nucleus accumbens. Eur J Neurosci 26:2046-2054.

Wise RA (2004) Dopamine, learning and motivation. Nat Rev Neurosci 5:483-494.

Yeomans JS (1989) Two substrates for medial forebrain bundle self-stimulation: myelinated axons and dopamine axons. Neurosci Biobehav Rev 13:91-98.

Yeomans JS, Maidment NT, Bunney BS (1988) Excitability properties of medial forebrain bundle axons of $\mathrm{A} 9$ and A10 dopamine cells. Brain Res 450:86-93.

You ZB, Wang B, Zitzman D, Azari S, Wise RA (2007) A role for conditioned ventral tegmental glutamate release in cocaine seeking. J Neurosci 27:10546-10555.

Zellner MR, Kest K, Ranaldi R (2008) NMDA receptor antagonism in the ventral tegmental area impairs acquisition of reward-related learning. Behav Brain Res 197:442-449.

Zhou FM, Liang Y, Dani JA (2001) Endogenous nicotinic cholinergic activity regulates dopamine release in the striatum. Nat Neurosci 4:12241229. 